\section{FUERTES ESPAÑOLES EN CHILOÉ: LAS HUELLAS DE LA HISTORIA EN MEDIO DEL PAISAJE INSULAR ${ }^{1}$}

Antonio Sahady Villanueva ${ }^{2}$

José Bravo Sánchez ${ }^{3}$

Carolina Quilodrán Rubio ${ }^{4}$

\section{Resumen}

La cultura chilota ha sido motivo de admiración creciente. Por su marco geográfico, por su historia, sus leyenda y sus mitos. También por su capital arquitectónico, casi siempre circunscrito a las iglesias y a las viviendas palafíticas. Pero es justo poner atención, también, a un tipo edificatorio no suficientemente investigado: las fortificaciones defensivas españolas. Localizadas en lugares de difícil acceso y sometidas a los rigores del clima, estas construcciones sembradas en los confines de América del Sur constituyen un testimonio insobornable de ciertos acontecimientos que explican su azaroso devenir. De aquellas fortificaciones hispanas subsisten unas cuantas ruinas que bien

\section{SPANISH FORTRESSES IN CHILOÉ: THE TRACES OF HISTORY WITHIN THE INSULAR LANDSCAPE ${ }^{1}$}

\author{
Antonio Sahady Villanueva ${ }^{2}$ \\ José Bravo Sánchez ${ }^{3}$ \\ Carolina Quilodrán Rubio ${ }^{4}$
}


merece la pena rescatar del olvido y el abandono, incorporándolas a un itinerario turístico que las ponga en valor.

\section{PALABRAS CLAVE: ARQUITECTURA MILITAR, FUERTES HISPANOS DE CHILOÉ, PATRIMONIO TANGIBLE Y SISTEMA DEFENSIVO DE CHILOÉ.}

Fecha de recepción: 07.03.11.

Fecha de aceptación: 10.06.11

1 Facultad de Arquitectura y Urbanismo. Universidad de Chile. Fondo FAU 2010.

2 Chile. Director, académico e investigador Instituto de Historia y Patrimonio de la Facultad de Arquitectura y Urbanismo, Universidad de Chile. Correo electrónico: asahady@uchilefau.cl

3 Chile. Académico e investigador Instituto de Historia y Patrimonio de la Facultad de Arquitectura y Urbanismo, Universidad de Chile.Correo electrónico: mbravo@uchilefau.cl

4 Chile. Académica e investigadora Instituto de Historia y Patrimonio de la Facultad de Arquitectura y Urbanismo, Universidad de Chile.Correo electrónico: cquilodran@uchilefau.cl

134 revista invi № 73 / Noviembre 2011 / Volumen № 26: 133-165 remain from these Spanish forts; such remains should be recovered and incorporated into tourist routes enhances their heritage value.

\section{KEYWORDS: MILITARY ARCHITECTURE, SPANISH FORTRESS IN CHILOE, TANGIBLE HERITAGE AND CHILOE'S DEFENSIVE SYSTEM.}

Received: 07.03.11.

Accepted: 10.06.11.

1 Facultad de Arquitectura y Urbanismo. Universidad de Chile. FAU Fund 2010

2 Chile. Director, academic and researcher, Instituto de Historia y Patrimonio, Facultad de Arquitectura y Urbanismo, Universidad de Chile.Email: asahady@uchilefau.cl

3 Chile. Academic and researcher, Instituto de Historia y Patrimonio, Facultad de Arquitectura y Urbanismo, Universidad de Chile.Email:mbravo@uchilefau.cl

4 Chile. Academic and researcher, Instituto de Historia y Patrimonio, Facultad de Arquitectura y Urbanismo, Universidad de Chile.Email: cquilodran@uchilefau.cl 


\section{Elementos arquitectónicos del Flandes Indiano presentes en las fortificaciones hispánicas de Chiloé}

Por definición, una construcción defensiva tenía que cumplir las siguientes funciones: cautelar el lugar donde se emplazaba, proteger las vías de comunicación terrestres y marítimas, salvaguardar a la población próxima a estas vías y, también, custodiar puntos de importancia estratégico-económica y militar, tales como puertos, pasos cordilleranos o ríos.

Al momento de elegir la localización territorial de una fortificación -fuerte o batería-, un ingeniero militar privilegiaba las zonas elevadas, como cerros o colinas, ya que permitían una vista panorámica del territorio cercano. Además, se escogían las salientes de afluentes o planicies costeras, como una manera de defender las vías de comunicación y el tránsito de tropas y colonos del ataque de enemigos nativos y extranjeros. Por último, "el establecimiento de una fortificación dependía de los insumos naturales que podía entregar el paisaje local, tanto para su construcción como para la sobrevivencia de la tropa: el agua, la madera, las piedras y los alimentos. En materia de armamento, en la fortificación no podian fal- tar cañones, pólvora, textiles y otras herramientas, habitualmente traídas desde el Perú por vía marítima".

Dimensionalmente, una fortificación poseía, por lo general, un tamaño que fluctuaba entre media hectárea y una hectárea. Las figuras más empleadas en la construcción de fuertes eran el cuadrado y el triángulo, que en muchos casos se complementaban con puntas triangulares o pentagonales. En esa superficie cabía, "en el mejor de los casos, una tropa de doscientos hombres; y si había caballería, era posible

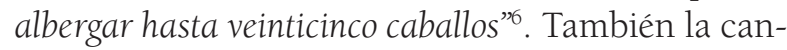
tidad de edificios militares estaba en estrecha relación con la dimensión del recinto castrense, "que comúnmente contaba con la casa del comandante; con los cuarteles para oficiales, los subalternos y la tropa; con la capilla, el almacén de pólvora y los pertrechos; el arsenal, la casa de guardia, los talleres y la herrería".

En un comienzo, el material constructivo que predominó en las fortalezas fue la madera. La abundancia de bosques permitía obtener firmes troncos que, atados con sogas, hacían de muros soportantes; y de allí provenían estacas y empalizadas. Posteriormente, se utilizó la fajina, el adobe, la piedra y el ladrillo. En el caso de Chiloé, la piedra cancagua fue la materia prima en la elaboración de muros; consiste en una roca sedimentaria de tipo arenisca, cuya principal condición es su maleabilidad.

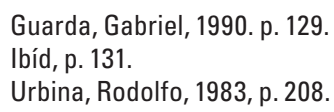


La muralla era el elemento estructurante principal de la fortificación. "Estaba conformada por tramos rectos llamados cortinas $y$, en los extremos, por puntas angulares, denominadas baluartes, que permitían

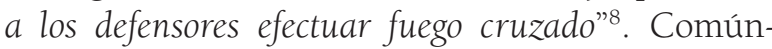
mente, las murallas eran construidas en tierra o fajina. A pesar de no resistir un ataque continuo de artillería, podía impedir la embestida de la infantería enemiga que intentaba ingresar a la fortaleza mediante alguna modalidad distinta a la escalada o el asalto de una brecha. De igual forma, se incluía muchas veces a la artillería en una plataforma principal o una banqueta usada por la infantería.

No menos importantes eran los baluartes, que debían tener un espacio considerable en sus flancos para la ubicación de, por lo menos, dos cañones que defendieran este lado del recinto. ${ }^{9}$ De lo contrario, un enemigo podía escalar y tomar el baluarte ante la imposibilidad de recargar un cañón.

Otra unidad destacable en la configuración de una fortaleza era el foso, el cual se extendía desde la base de la muralla hasta un camino cubierto. También podía agregar otros elementos defensivos complementarios como el hornabeque, las lunetas, el revellín y las tenazas, entre otros. ${ }^{10}$ En su parte externa contaba con una contra escarpada, que era

Guarda, op. cit., p. 285

Urbina, op. cit., p. 214.

Vargas Guarategua, Javier, 2007. p. 108. una pared continua que reproducía las formas de los baluartes.

Como último componente destacable en la constitución defensiva de un fuerte estaba el glacis, ${ }^{11}$ que correspondía a un terreno abierto en relación con el perímetro de la fortificación y cuya distancia iba desde el camino cubierto hasta la misma fortaleza, con una pendiente muy leve. Su principal función era obligar a la hueste contraria a desgastarse en un dilatado y trabajoso asalto regular. En este caso, debían evitar los disparos y cañonazos provenientes del fuerte, realizando para ello trincheras para salvaguardar sus vidas. Por otro lado, se presentaba la dificultad de trasladar y disparar los cañones desde la pendiente del glacis hacia la fortaleza atacada.

Finalmente, la resistencia del material empleado y las eficientes técnicas constructivas utilizadas por los ingenieros militares hicieron posible que algunas edificaciones defensivas se conserven hasta nuestros días. En efecto, lograron soportar, por una parte, el ataque de indígenas e invasores extranjeros; por otra, los temporales sureños, los procesos erosivos, la invasión de la vegetación, las catástrofes naturales, los incendios, el paso del tiempo. Y, sobre todo, el descuido y el abandono (figura 1).

11 Ibídem. 
FIGURA 1. ACUARELA DEL FUERTE DE AGÜI DE E. COURTOIS DE BONNENCONTRE, QUE MUESTRA EL ESTADO DE ABANDONO EN 1911.

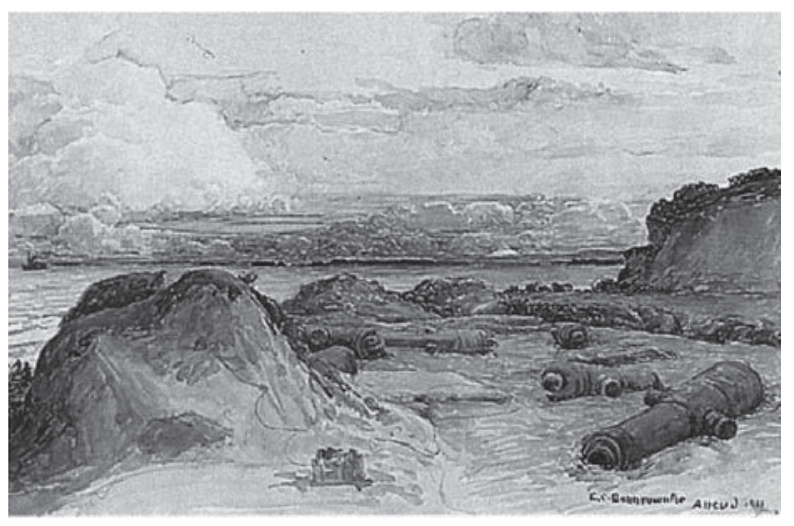

FUENTE: Guarda, 1990.

\section{Composición del Sistema Defensivo Español diseñado para la protección de Chiloé}

A mediados del siglo XVI, la construcción de fortificaciones en Chile respondía a los conocimientos prácticos de los primeros descubridores, conquistadores y colonizadores del nuevo territorio. Por lo tanto, eran edificaciones muy "sui generis" que, por lo general, correspondían a precarias empalizadas. Martín Ruiz de Gamboa, por ejemplo, junto con fundar la ciudad de Santiago de Castro, decidió construir, al mismo tiempo, un fuerte que la defendiera de cualquier adversario en 1567.

Procedentes de Italia llegaron a América, posteriormente, algunos ingenieros al servicio de la Corona Española que no tardaron en diseñar y erigir fortificaciones de calidad. Más tarde, ya a finales del siglo XVI y comienzos del XVII, esta labor fue asumida por ingenieros hispanos expertos en la Guerra de Flandes e Italia. Se dio origen, entonces, al llamado "Flandes Indiano", término acuñado por Diego de Rosales para definir el estilo y modo ingenieril y arquitectónico en la construcción de fortificaciones en Chile.

El rótulo de "Flandes Indiano" alude a la similitud que se da entre la situación vivida en Chile y la de Flandes: en tierras europeas los tercios españoles libraron violentas batallas contra sus adversarios, ${ }^{12}$ semejantes batallas se repetían en esta parte de América, ahora frente a la fiera resistencia araucana, a partir del tiempo de la conquista, con fatídicos resultados para las huestes españolas.

En mitad del siglo XVII, la construcción de fuertes estuvo a cargo del Real Cuerpo de Ingenieros Militares de España, con sede en la ciudad de Madrid. A ellos correspondió desarrollar nuevas técnicas defensivas, que aplicaron con eficacia en la construcción de fortalezas. Cabe reconocer que

12 Guarda, op. cit., p. 260. 
rara vez visitaron Chile. Pero, aun cuando enviaban delegados para que cumplieran su misión en estas latitudes, su participación se hacía patente en el reforzamiento de las fortificaciones del territorio comprendido entre Valdivia y el Estrecho de Magallanes. Un ejemplo es el "Antemural del Pacífico", ${ }^{13}$ que debía proteger los Reinos de Chile y Perú de las incursiones e invasiones de otras potencias europeas interesadas en apoderarse del paso del Cabo de Hornos y de las tierras australes.

Ya en el siglo XVIII los ingenieros militares se anticiparon a introducir en sus diseños arquitectónicos el sello neoclásico propio de las fortificaciones de la época. Convirtieron, por lo demás, estas construcciones defensivas en centros de expansión territorial, agrícola y comercial. Ejemplo de ello es, en el caso de Chiloé, la apertura del camino de Caicumeo, que unió los poblados de San Carlos de Ancud y Santiago de Castro.

El rol disuasivo que trajo consigo la construcción de las fortificaciones a partir de mediados del siglo XVII -la idea era intimidar a los adversarios europeos de la Corona Española interesados en la parte meridional del Pacífico-, dio como resultado la conservación de los territorios al sur de Valdivia. Se cumplía la máxima "si vis pacem, para bellum" (si quieres paz, prepárate para la guerra). Los fuertes eran, precisamente, avales de la paz y el mantenimiento territorial para el Rey de España en América, lo que llevaba consigo una homogeneidad cultural y religiosa en este finis terrae. Guarda sostiene que en Chile se erigieron alrededor de 225 fortificaciones en el arco de tiempo que media entre el siglo XVI y el año 1826. De esas fortificaciones, 27 de ellas estaban en relación con el dominio territorial de Chiloé. ${ }^{14}$

La estructura del sistema defensivo de Chiloé estaba conformada por cuatro zonas:

- La primera, a cargo de los fuertes de San Carlos de Ancud y de Agüi y sus correspondientes baterías. Éstos dominaban la costa meridional de la entrada y el centro del Canal de Chacao.

- La segunda estructura estaba constituida por el fuerte de Carelmapu y sus baterías, que debían custodiar el borde marino septentrional del paso de Chacao, desde su acceso hasta el sector de Pargua.

- La tercera estaba a cargo del Fuerte de Chacao y sus recintos menores, los que debían proteger al canal del mismo nombre y el fondeadero.

- Y la cuarta, correspondiente al área del centro de la Isla Grande, de la que dependía el puerto interior y el fuerte de Castro.

13 Vargas Guarategua, Javier, op. cit., p. 98.

14 Guarda, Gabriel, op. cit., p. 370. 
FIGURA 2. PUNTA GUAPACHO, LUGAR DONDE SE EMPLAZABA EL PUESTO DE CENTINELA HOMÓNIMO, QUE CUSTODIABA Y DABA AVISO DE LA ENTRADA DE ALGÚN ENEMIGO DE LA CORONA ESPAÑOLA EN LA BOCA DEL CANAL DE CHACAO.

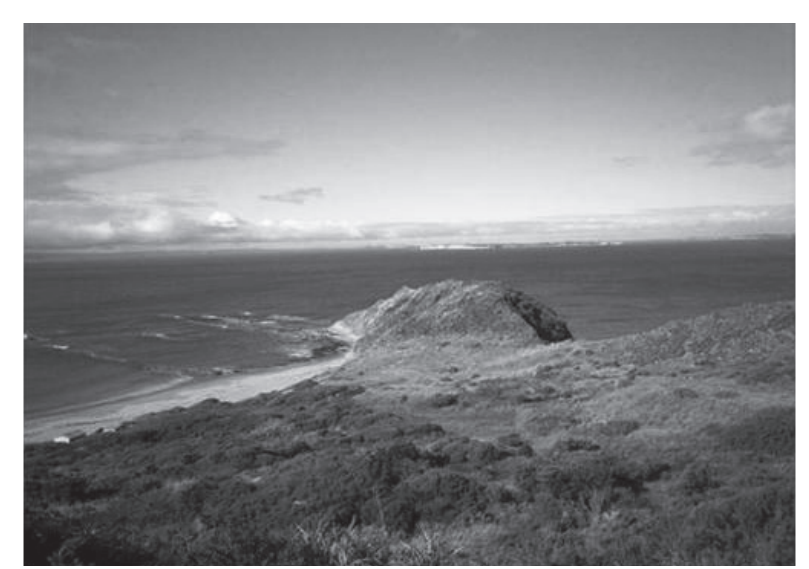

Instituto de Historia y Patrimonio. 2010.

El sistema defensivo chilote, a su vez, estaba dividido en tres niveles interconectados y dependientes entre sí: los centinelas, las baterías y los fuertes.

En su nivel básico, una agrupación de centinelas o vigías debía custodiar, en turnos de día y noche, las dos riberas de la entrada del Canal de Chacao; y en Cucao (en el caso de Castro), por medio de una red de posta. ${ }^{15}$ Así, ante la incursión de una

15 Ibíd, p. 29.
FIGURA 3. CAÑONES DE BATERÍA DE SAN ANTONIO, ENFRENTANDO AL CANAL DE ANCUD.

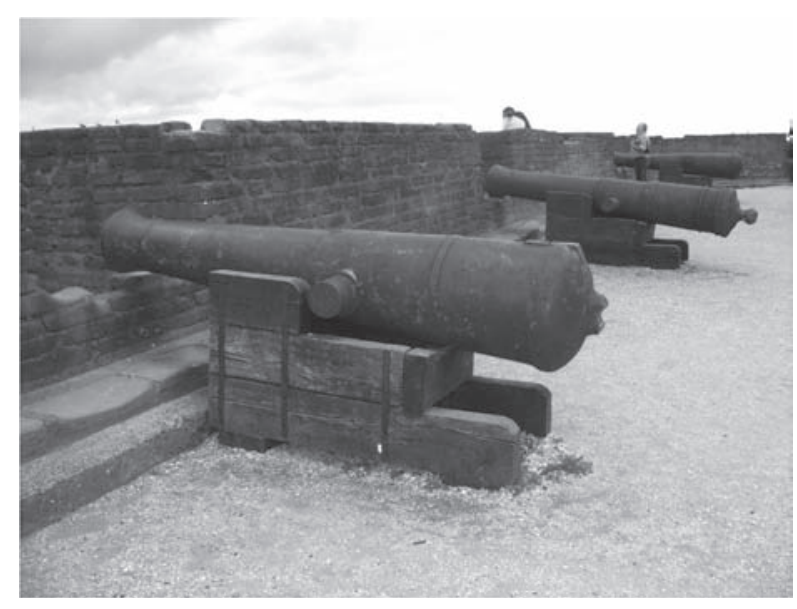

Instituto de Historia y Patrimonio. 2010.

nave extranjera o la detección de otro suceso anómalo, daban aviso por medio de disparos o señales de humo, susceptibles de ser divisados por la guardia de una batería o un fuerte. Era el modo de alertar tanto a civiles como a militares de un posible ataque. Una vez que el centinela advertía la entrada de un enemigo por el paso oceánico o ribereño, entraba en función defensiva el segundo nivel: las baterías (ver figura 2). 
Las baterías chilotas tenían el carácter de marítimas debido a su localización costera y provisional, en relación con la intermitente ocupación de una tropa: la espesura de los bosques y la alta pluviometría de Chiloé hacían casi inhabitable los sectores en que se emplazaban, a excepción de los escasos periodos de buen clima. Por lo demás, sólo entraban en combate en tiempos de guerra, cuando el contingente militar era suficiente como para hacer uso de la abundante fusilería que provenía de la Madre Patria (ver figura3).

Ya advertidas de la presencia de un invasor, las baterías respondían automáticamente a través del fuego de sus cañones que, por lo general, estaba compuesto de seis piezas de artillería. Los cañonazos debían alcanzar, como máximo, hasta la mitad del cuerpo de agua, donde las corrientes marinas ejercían un rol cómplice: contribuían a acercar a las naves intrusas hacia la ribera, exponiéndolas a los disparos de los puestos militares.

En el tercer nivel del sistema defensivo entraban en acción los fuertes. Un fuerte en Chiloé, según fuese su emplazamiento y función, podía ser catalogado de marítimo o de interior. El primero se emplazaba en el borde costero y su función defensiva era externa, toda vez que protegía a la provincia de las agresiones de piratas, corsarios y armadas enemigas (es el caso de los fuertes de San Carlos, Agüi, Carelmapu y Chacao). El segundo, en cambio, estaba asociado a la defensa interior del archipiélago, ya que evitaba embestidas y sublevaciones de los pueblos originarios chilotes, hacia los colonos hispanos y mestizos.
Por otra parte, los fuertes se consideraban estables (o permanentes), capaces de resistir las enérgicas embestidas del enemigo. Eran, al final de cuentas, construcciones indispensables, en cuya estructura no podían faltar ciertos elementos defensivos: un foso con estacada en su interior, recintos de sólida factura para albergar cuarteles, arsenales y almacenes. Se precisaba, además, espacio para contener cañones de reserva. Y, encima, contar con material suficiente como para edificar, en los aledaños, más baterías provisionales en tiempos de guerra (ver figura 4).

\section{FIGURA 4. CHACAO VIEJO, LUGAR DONDE SE EMPLAZABA EL ANTIGUO FUERTE DE SAN ANTONIO DE CHACAO, ACTUALMENTE ES OCUPADO POR LA CAPILLA DEL POBLADO.}

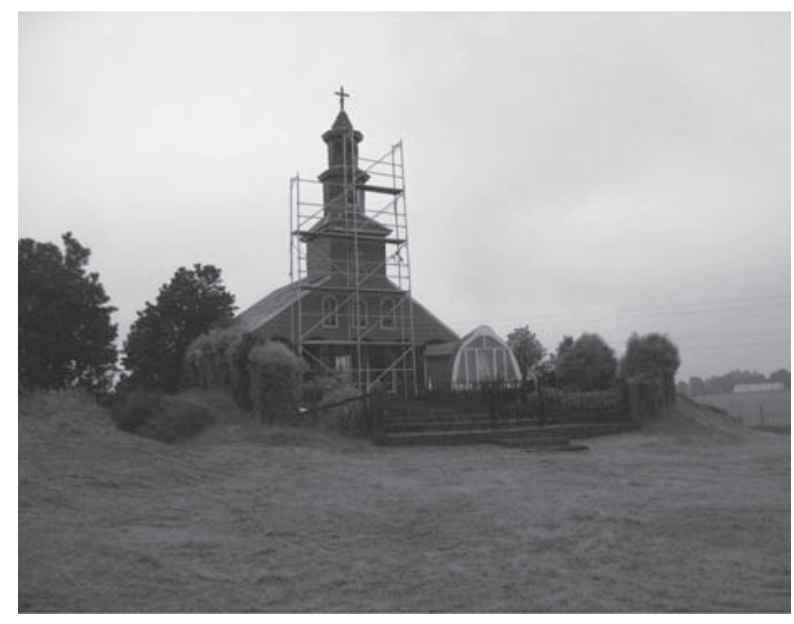

Instituto de Historia y Patrimonio, 2010. 
En términos generales, los fuertes que entraban en combate contaban con una importante dotación de oficiales, tropa regular y milicias y abrían fuego con no menos de diez cañones.

\section{Catálogo del Sistema Defensivo Hispano de Chiloé}

Entre los años 2009 y 2010 un grupo de académicos del Instituto de Historia y Patrimonio de la Facultad de Arquitectura y Urbanismo de la Universidad de Chile desarrolló una investigación relacionada con las fortificaciones hispánicas en el archipiélago de Chiloé, que consideró dos ámbitos de estudio: el primero, abarcando la antigua estructura del sistema defensivo hispano; el segundo, los lugares históricos de batallas de la Campaña Emancipadora de Chiloé (1820-1826). El universo de casos se concentra en dos sectores, comprendidos entre los $41^{\circ} 44^{\prime}$ y $42^{\circ} 33^{\prime}$ de Latitud Sur y los $73^{\circ} 54^{\prime}$ y $73^{\circ} 39^{\prime}$ de Longitud Oeste. El primero corresponde a la parte continental de la costa septentrional del Canal de Chacao; el segundo, al sector norte y centro de la Isla Grande de Chiloé (ver figura 5).

El sector bañado por el Canal de Chacao está compuesto por:

- Subsistema Carelmapu.
- Subsistema Lacuy.

- Subsistema San Carlos de Ancud.

- Subsistema San Antonio de Chacao.

El sector perteneciente a la Isla Grande de Chiloé, por su parte, está conformado por el Subsistema Castro-Tauco.

\section{SUBSISTEMA CARELMAPU}

Corresponde a los componentes del sistema de defensa de Chiloé, en el sector septentrional del canal de Chacao. Está conformado por el Fuerte Carelmapu, el centinela de Astillero y la batería de Coronel. La distancia que separa a los más extremos es de 21,5 km (ver figura 6).

En el caso del fuerte de Carelmapu, construido en madera y fajina desde 1603, actualmente su ubicación exacta es difusa debido a que está cubierto por la vegetación del bosque nativo de esta zona, lo cual hace un difícil acceso al lugar donde estuvo emplazado originalmente. Sin embargo, es posible encontrar cañones y algunos muros que testimonian la presencia de la antigua fortificación en medio del exuberante follaje.

Del puesto de centinela de Astillero no existen vestigios que den cuenta de la presencia de esta batería. En su lugar se sitúa actualmente el poblado de Astilleros, un camino que lleva a una pequeña playa donde desemboca el estero homónimo. 
FIGURA 5. MAPA DEL ÁREA DE INFLUENCIA DEL SISTEMA DEFENSIVO ESPAÑOL DE CHILOÉ.

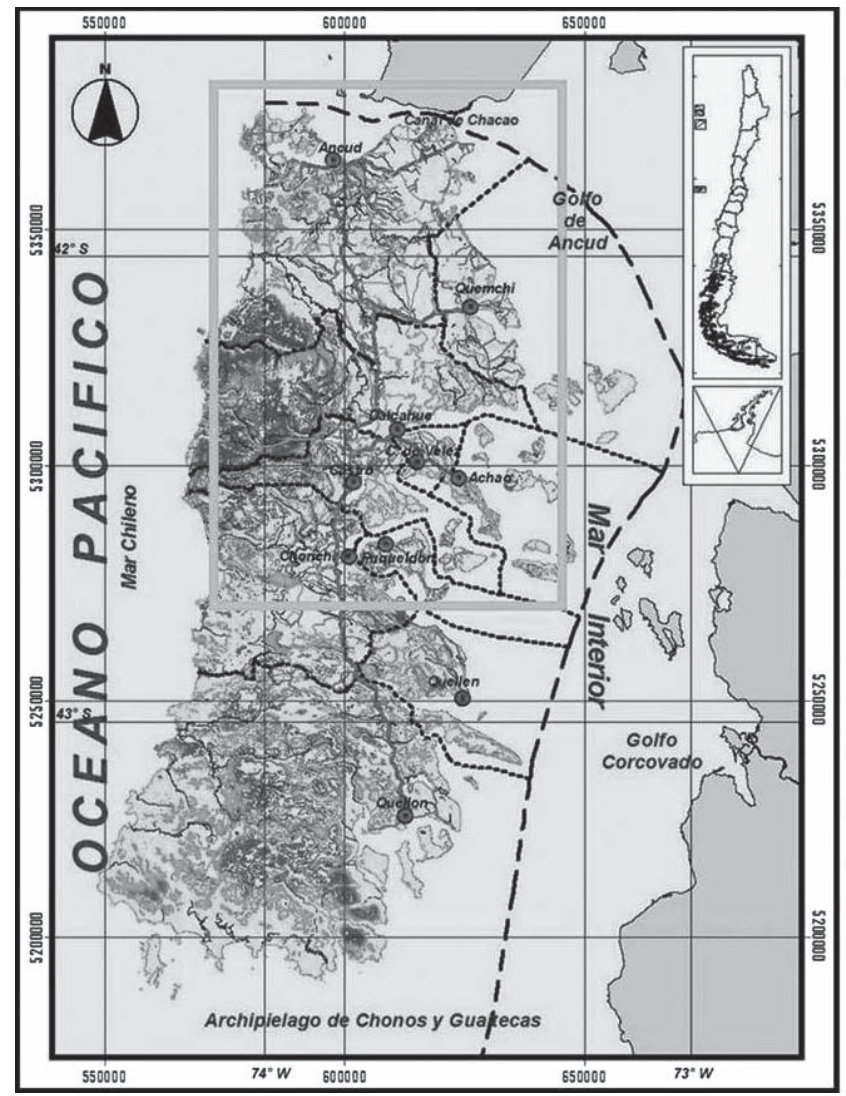

\begin{tabular}{|c|c|c|}
\hline \multicolumn{3}{|c|}{$\begin{array}{l}\text { AREA DE ESTUDIO DE FUERTES HISPANOS Y } \\
\text { LUGARES HISTORICOS DE LA PROVINCIA DE CHILOE }\end{array}$} \\
\hline \multicolumn{3}{|c|}{\begin{tabular}{lc} 
Capital Comunal. & Area de Estudio. \\
Tipos de Caminos. & Curvas de Nivel. \\
Pavimentado & $0-100$ \\
Ripiado & $101-200$ \\
Huella & $201-375$ \\
Limites & $376-600$ \\
JProvincial & $601-800$ \\
\hdashline Comunal. & Hidrologia \\
Otros. & Rios. \\
$\square$ Archipielago de Chiloé & Linea de Costa. \\
& Region de Los Lagos. \\
Mar. & Rio. \\
Lagos. &
\end{tabular}} \\
\hline \multicolumn{3}{|c|}{$\begin{array}{l}\text { Titulo de Práctica } \\
\text { Estudio Preliminar de los Espacios Históricos Chilotes } \\
\text { ysu Valorización como Lugares de Patrimonio Cultural. } \\
\text { Campaña de Chiloé (1820-1826). }\end{array}$} \\
\hline $\begin{array}{l}\text { Ubicación } \\
\text { Provincia de Chiloé. } \\
\text { Región de Los Lagos }\end{array}$ & $\begin{array}{l}\text { Superfi } \\
9.181,6\end{array}$ & $\begin{array}{l}\text { icie de Area de Estudio } \\
\mathrm{Km}^{2}\end{array}$ \\
\hline \multicolumn{3}{|c|}{$\begin{array}{l}\text { Fuente } \\
\text { I.G.M. CartasTopográficas. Puerto Montt. } \\
\text { Castro. Isla Guafo. Escala 1: } 250.000 \text {. }\end{array}$} \\
\hline \multicolumn{3}{|c|}{ 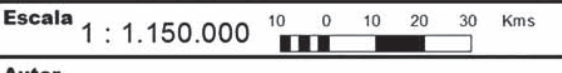 } \\
\hline \multicolumn{3}{|c|}{$\begin{array}{l}\text { Autor } \\
\text { Manuel Fernando Ordenes González }\end{array}$} \\
\hline \multicolumn{3}{|l|}{$\begin{array}{l}\text { Fecha de Elaboración } \\
\text { Junio - Julio } 2008 .\end{array}$} \\
\hline \multicolumn{3}{|c|}{$\begin{array}{l}\text { Institución } \\
\text { UNIVERSIDAD DE CHLE } \\
\text { InReAr } \\
\text { FACULTAD DE ARQUITECTVRA Y URBANISMO } \\
\text { INSTIUUTO DE RESTAURACOON ARQUITECTONICA } \\
\text { INREAR }\end{array}$} \\
\hline
\end{tabular}

Instituto de Historia y Patrimonio. 2010. 
FIGURA 6. MAPA DE UBICACIÓN DE LOS ELEMENTOS DEFENSIVOS DEL SUBSISTEMA CARELMAPU.

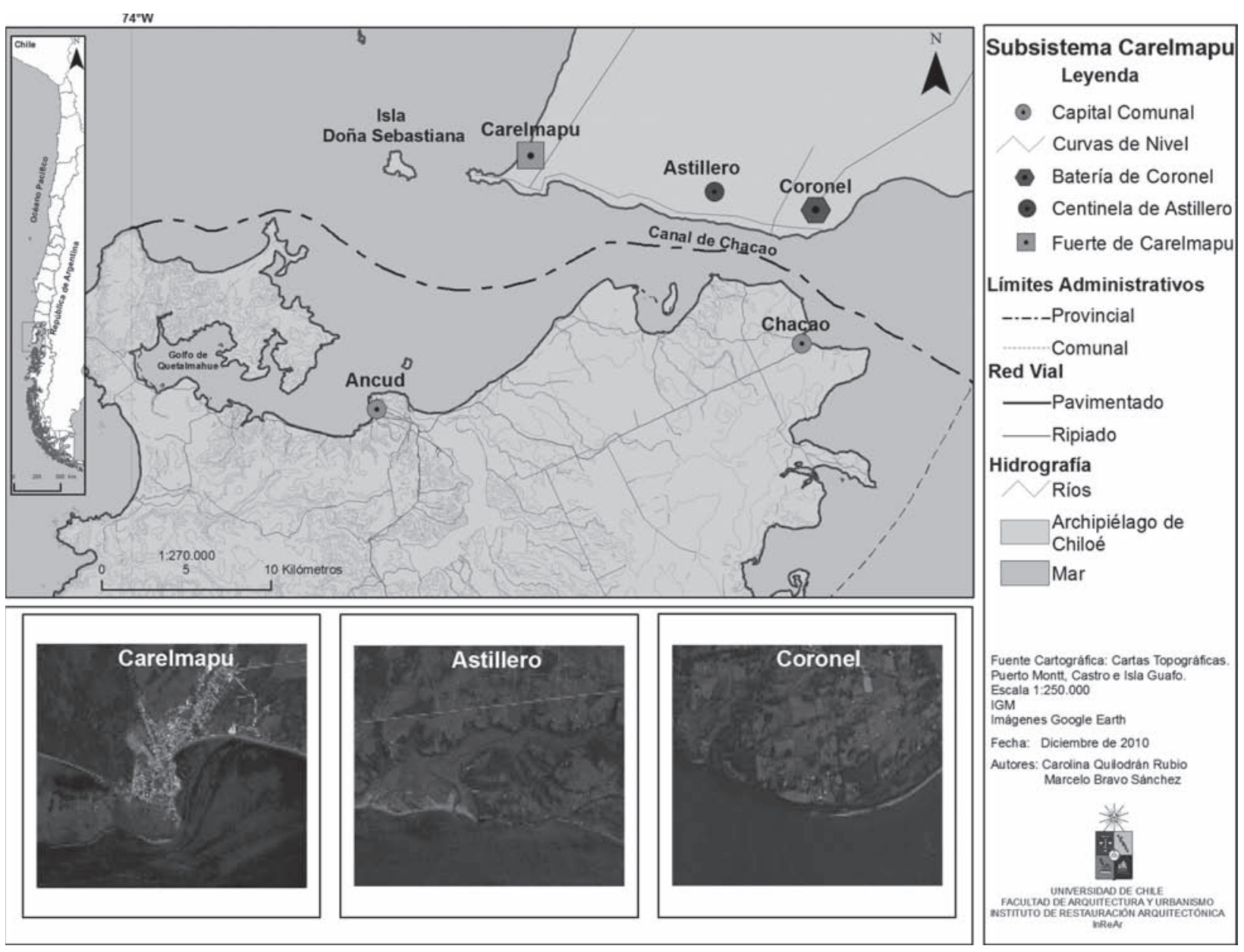

Instituto de Historia y Patrimonio. 2010. 
Por último, de la batería de Coronel tampoco existen rastros ni testimonios. En su lugar, en la parte alta de la meseta, no hay más que un inofensivo paisaje rural, armado de una sobria casa patronal con sus correspondientes campos de cultivo y pastoreo. Próxima a este lugar se emplaza su playa de arena, vecina a un acantilado, donde se ha instalado una rampa pavimentada que permite el desembarco de los vehículos que descienden de aquellos ferryboats que realizan la travesía Chacao-Pargua. Esta rampa se conecta con la costa mediante un camino pavimentado que une la localidad de Punta Coronel con el pueblo de Chacao Nuevo.

\section{SUBSISTEMA LACUY}

Corresponde a los componentes del sistema de defensa de Chiloé, en el sector meridional del canal de Chacao, en la Península de Lacuy, desde Punta Guapacho hasta Punta Balcacura. De oeste a este, se descompone en: el centinela de Guapacho o Huapacho, la batería de Corona o Guapilacuy, el fuerte Agüi, la batería de Chaicura y la batería de Barcacura o Balcacura (su topónimo significa "Isla de piedra porosa"). La distancia entre sus partes extremas es de $24 \mathrm{~km}$, a lo largo de la costa meridional de la entrada del Canal de Chacao (ver figura 7).

Acerca del puesto de Centinela de Guapacho, no existen testimonios exactos de su emplazamiento. Sin embargo, en su lugar se halla un acantilado ro- coso con escasa vegetación litoral, lo cual se expresa en un acceso dificultoso a él.

De igual modo, de la condición de la batería de Corona, tampoco hay huellas de su emplazamiento. En su lugar se ha emplazado un faro que lleva su nombre, cuyo edificio funciona como estación meteorológica y como estación de control de tráfico marítimo.

Mientras que el fuerte de Agüi o Ahui se encuentra en una condición de abandono. Mas, es considerado un muy importante foco turístico en Ancud, puesto que se le reconoce su valor patrimonial, histórico y arquitectónico. Por ello, se siguen haciendo esfuerzos por mantener en buen estado de conservación sus muros y su artillería.

Siguiendo con el análisis, está la batería de Chaicura que al igual que la anterior fortificación, está en un estado lastimoso y abandonado. Solamente posee una forma difusamente trapezoidal. Como testimonio visual sólo superviven, a modo de solevantamientos, los puntos donde estuvieron los parapetos destinados a la artillería de barbeta.

En idéntica condición se encuentra la batería de Balcacura. Un exuberante bosque integra a esta fortificación con un caserío rural adyacente. Su límite opuesto es un acantilado que da al mar, junto a cuya orilla se extiende una angosta playa, dejando de este modo el presunto lugar donde se emplazaba dicha fortificación. 
FIGURA 7. MAPA DE UBICACIÓN DE LOS ELEMENTOS DEFENSIVOS DEL SUBSISTEMA LACUY.
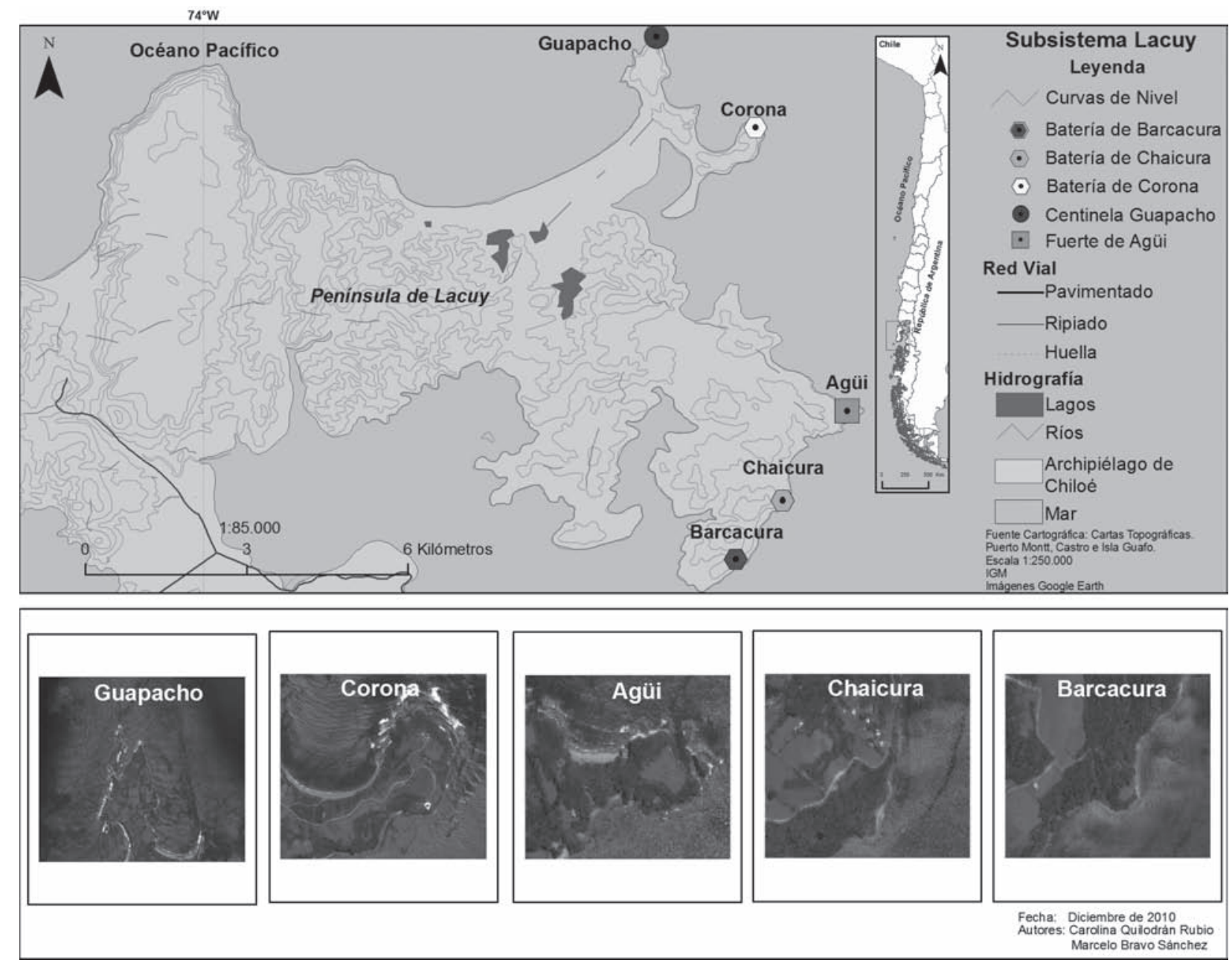

Instituto de Historia y Patrimonio. 2010. 
Vale la pena destacar que tanto la batería de Chaicura como la de Balcacura están en un proceso de restauración por el Plan Chiloé del MOP de 2010.

\section{SUBSISTEMA SAN CARLOS DE ANCUD}

Se encuentra en el sector meridional del Canal de Chacao, en la Península de Hueihuen, entre Punta San Antonio y Punta Piedras. Sus componentes son, de norte a sur, el Fuerte Real de San Carlos de Ancud, las baterías de Punta Teque y el Fuerte San Antonio, la batería de Campo Santo o Camposanto, la batería del Muelle y la batería de Poquillihue o Puquillihue. La distancia entre sus puntos extremos -la costa meridional y el fondeadero de Ancud-es de 3,4 km (ver figura 8).

En el caso de la batería de Poquillihue, a pesar de ser declarada Monumento Histórico en 1926, no hay vestigios de aquel recinto militar, ya que en su lugar se encuentra un conjunto de viviendas muy heterogéneas entre sí.

Análogamente, la situación de las baterías del Muelle, Campo Santo y Punta Tecque no es muy diferente, puesto que no existen rastros de estas baterías emplazadas en el borde costero de la ciudad de Ancud. Debido a los procesos de modernidad que

146 revista invi № 73 / Noviembre 2011 / Volumen № 26: 133-165 ha sufrido la costanera de esta ciudad, que es una vía de permanentes transformaciones, ni siquiera están presentes en la memoria de los ancuditanos.

En cuanto al Fuerte Real de San Carlos, mandado a construir por el Gobernador Quintanilla en 1824, sólo queda un edificio conocido como "El Polvorín", que está en medio de una pequeña plaza cívica.

Finalmente, la batería de San Antonio ha sido la excepción en su estado de conservación, puesto que de esta estructura se mantienen en buen estado un torreón y una reja de fierro que anuncian la entra$\mathrm{da}^{16}$, que además de su batería compuesta por sus cañones y parapetos. Lo cual hace un paseo obligado tanto para turistas como para residentes debido a la excelente conservación de esta batería española.

\section{SUBSISTEMA SAN ANTONIO DE CHACAO}

Este subsistema está conformado por el fuerte y las baterías del sector costero de Chacao, en la parte norte de la Isla Grande de Chiloé. Su área de influencia va desde Punta Remolinos hasta el poblado de Chacao Viejo. De norte a sur se descompone en la batería de Remolinos, la batería de Pampa de Lobos, la batería de La Poza y el fuerte San Antonio de Chacao. La distancia entre sus piezas extremas

16 En la parte superior del pórtico, una imagen representa dos cabezas de león, separadas por un cañón y una leyenda que contiene el nombre y la fecha de construcción de la batería. Flanqueando la representación central existen sendos heraldos: uno correspondiente a la ciudad de Ancud y, el otro, a la Corona Española. 


\section{FIGURA 8. MAPA DE UBICACION DE LOS ELEMENTOS DEFENSIVOS DEL SUBSISTEMA SAN CARLOS DE ANCUD.}

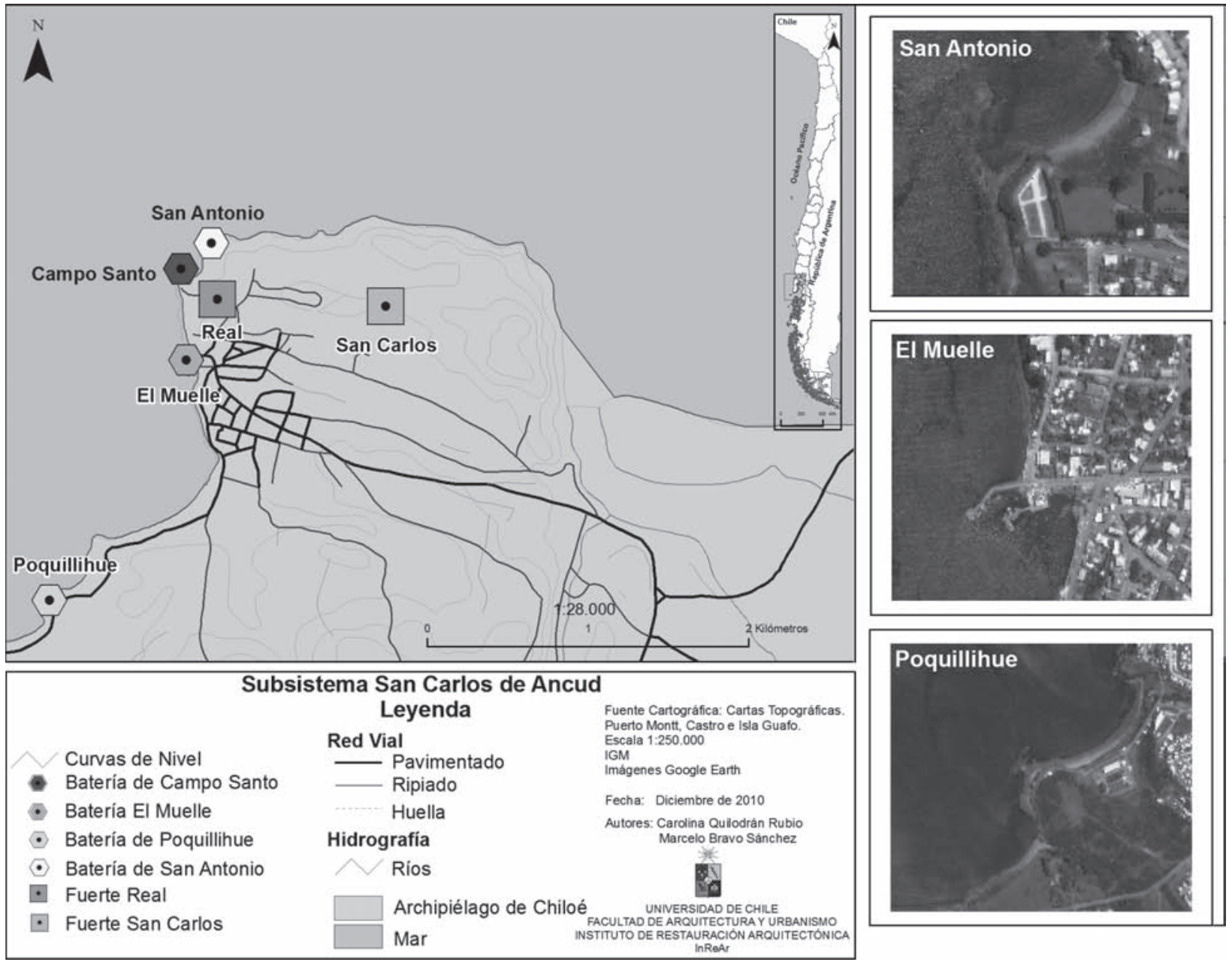

Instituto de Historia y Patrimonio. 2010 
es de 3,6 kms de la costa meridional del Canal de Chacao (ver figura 9).

En relación a las baterías de Remolinos, Pampa de Lobos y La Poza, tampoco existen testimonios de su presencia. Es así como de la primera de ellas solamente existe una antena de telecomunicaciones que emerge en medio de un extenso terreno baldío; sin embargo, algunos lugareños de Chacao Nuevo recuerdan que hace cuatro décadas quedaban restos de cañones en ese lugar. Mientras que en Pampa de Lobos sólo existe un despoblado terreno, escarpado y rocoso, de difícil acceso y que no da señales de su antigua presencia. Y en el sector de La Poza, en el lugar donde estuvo, hoy desembarcan los ferry-boats que provienen desde el muelle continental de Pargua y se dirigen hasta el atracadero de Chacao. Los continuos trabajos de modernización en este sector han borrado todo su rastro, solamente registrándose en las investigaciones de Guarda en los años 1990 y 2009, que ilustran acerca de su existencia.

En cuanto al fuerte de Chacao Viejo, sólo es recordado por una explanada de pasto, donde antiguamente estuvo el foso. Destacándose la parte norte donde se alza la iglesia del pueblo de Chacao Viejo. Mientras que unos leves solevantamientos en el césped aluden a los antiguos muros de la fortificación. Haciendo de este modo que los historiadores chilotes hayan incorporado este fuerte en sus registros y los lugareños, en la tradición oral.

\section{SUBSISTEMA CASTRO-TAUCO}

Conformado por el fuerte y las baterías de la ribera oriental del Estero Castro, en el centro de la Isla Grande de Chiloé, su área de influencia va desde la misma ciudad de Castro hasta Punta Tauco. De norte a sur cuenta con el fuerte Santiago Apóstol de Castro, la batería de Castro y la batería de Tauco. La distancia entre sus posiciones extremas es de $18 \mathrm{~km}$, en plena ribera del Estero Castro (ver figura 10).

Es paradójico que siendo Castro la principal ciudad de Chiloé, no se hayan conservado sus dos fortificaciones, expresadas en su fuerte y batería marítima correspondientes, producto de la vorágine modernizadora ocurrida tanto en el centro como en el sector costero de esta urbe que no respetó los materiales en que fueron construidos estos recintos (madera y fajina). Por lo cual, sólo resta valerse de los relatos históricos y de las fuentes cartográficas de la época colonial de Chiloé.

No obstante, otra excepción a la suerte que sufrieron las fortificaciones chilotas ha sido el fortín de Tauco, que además de ser declarado Monumento Histórico en 1926, se ha convertido en un parador turístico, al cual se llega a través de un camino serpenteante y ripioso. Este conjunto procura evocar la batería antigua: una explanada en forma de "M", un parapeto de madera, tres cañones de fierro de calibre 24. 
FIGURA 9. MAPA DE UBICACIÓN DE LOS ELEMENTOS DEFENSIVOS DEL SUBSISTEMA SAN ANTONIO DE CHACAO.
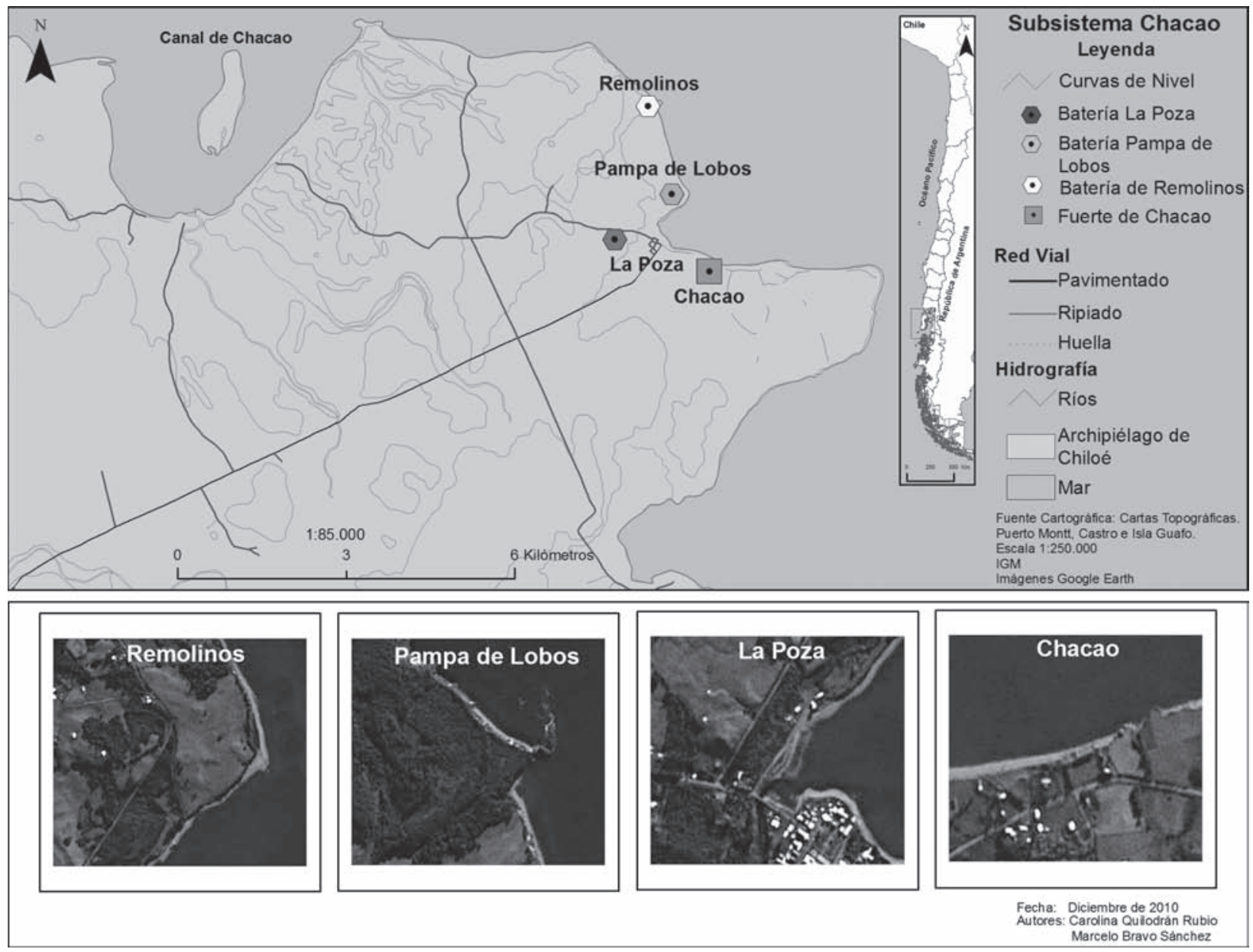

Instituto de Historia y Patrimonio. 2010. 
FIGURA 10. MAPA DE UBICACIÓN DE LOS ELEMENTOS DEFENSIVOS DEL SUBSISTEMA CASTRO-TAUCO.

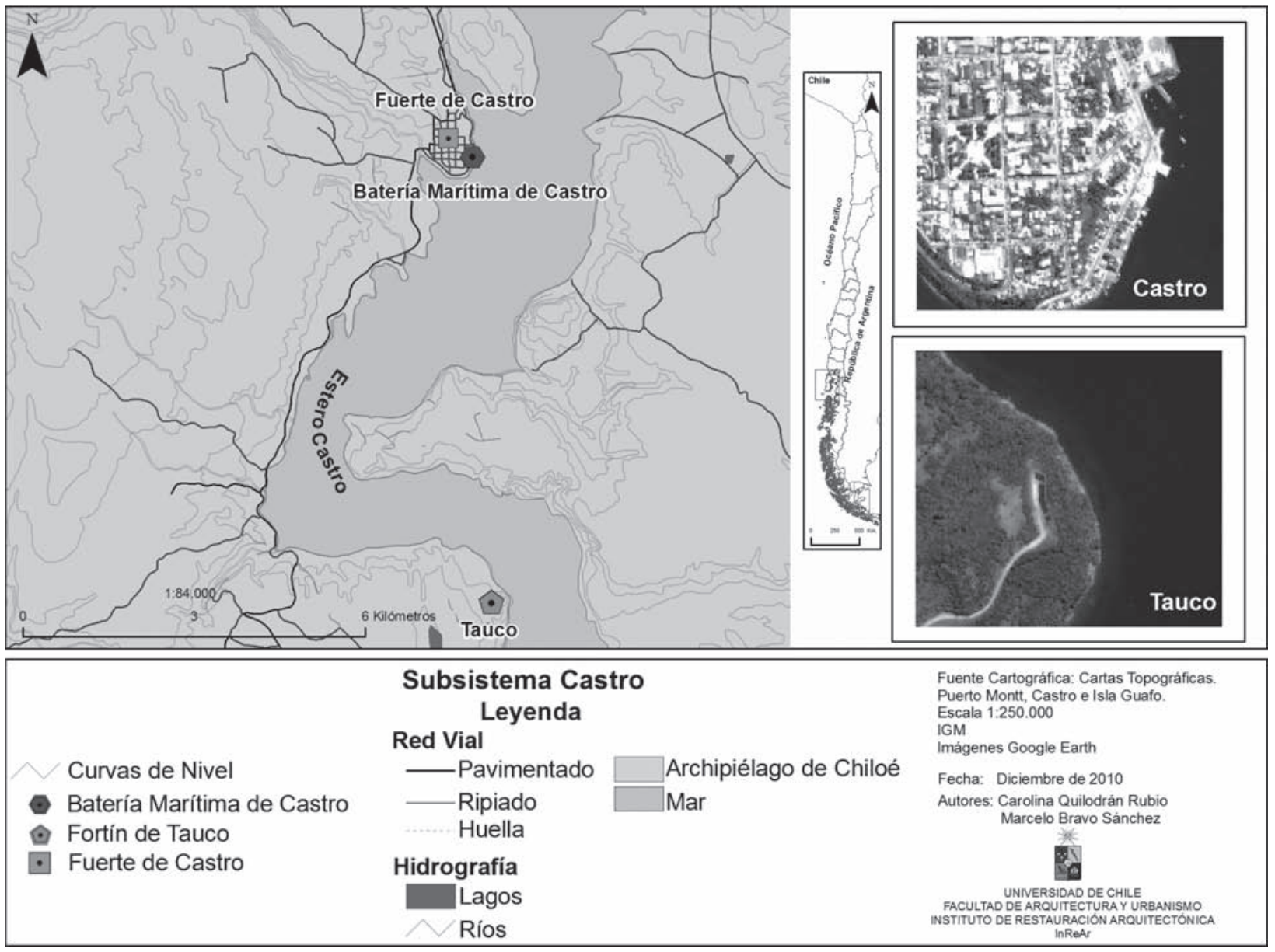

Instituto de Historia y Patrimonio. 2010. 


\section{Análisis de los factores que permiten determinar el grado de recuperación de los Fuertes Hispanos y los Lugares de Batalla de la Campaña Chiloé (1820-1826) en la Provincia de Chiloé}

Este punto aborda los factores mediante los cuales se puede mensurar la actual condición de los Fuertes Hispanos en el territorio insular y, consecuentemente, las posibilidades de recuperación de esos focos patrimoniales. El propósito final es exhumarlos del abandono y del olvido, de manera que pasen a formar parte de un circuito de interés turístico cultural.

Cabe precisar que en una primera etapa -en gabinete- se logró registrar 20 espacios históricos relacionados con el sistema defensivo hispano de Chiloé, de los cuales un 35\% de la totalidad de los casos estudiados se pueden apreciar sus vestigios o gran parte de su estructura original. El 65\% restante solamente aparece en textos históricos que dan indicios de sus emplazamientos geográficos.

Durante la investigación se fueron respondiendo las siguientes interrogantes acerca del estado de las fortificaciones hispánicas en Chiloé y su devenir:
¿Cuál es el estado de conservación actual de los Fuertes Hispanos? ¿Quedan vestigios de estas fortificaciones? ¿Cuál es la percepción histórica que se tiene de ellas? ¿Tienen suficiente importancia histórica como para que merezcan una investigación? ¿Como para incorporarles una adecuada señalética? ¿Como para organizar un programa de visitas? ¿O es que el fenómeno de la globalización ha terminado por reemplazar las banderas de la identidad?

La información histórica, patrimonial y arquitectónica de la etapa de gabinete y los datos recaudados tanto por el Consejo de Monumentos Nacionales como por la Dirección de Arquitectura del Ministerio de Obras Públicas han sido necesariamente complementados por el equipo de investigadores que ha estado en terreno. Del análisis y evaluación ha derivado la definitiva selección de los casos estudiados. Asimismo, se han definido seis factores de análisis que permiten comprender la situación actual de cada uno de los casos. Y, a partir de los resultados, determinar el grado de recuperación posible, incorporándolos al erario patrimonial del archipiélago.

Los factores de análisis son los siguientes:

- Estado de Conservación

- Percepción Histórica

- Importancia Histórica

- Accesibilidad

- Señalética

- Cantidad de Visitantes 


\section{ESTADO DE CONSERVACIÓN DE LA OBRA}

Esta condición habla del verdadero estado material del bien investigado, sea este de naturaleza tangible o inmaterial (los restos de una instalación defensiva o un lugar histórico). En el caso de los lugares históricos, su estado actual se puede medir en el grado de familiaridad que proyectan en la vida cotidiana -O en la memoria- de los lugareños. ¿Están presentes los hechos del pasado en la vida del chilote? ¿Cuánto gravitan en su propia historia y en la de sus antepasados?

Aun cuando la mayor parte de los casos son incomparables entre sí, de una manera algo más perceptual que científica se han definido seis grados del estado de conservación de un lugar histórico, a saber:

\section{GRÁFICO N 1. LUGARES HISTÓRICOS DE CHILOÉ EN RELACIÓN CON SU ESTADO DE CONSERVACIÓN.}

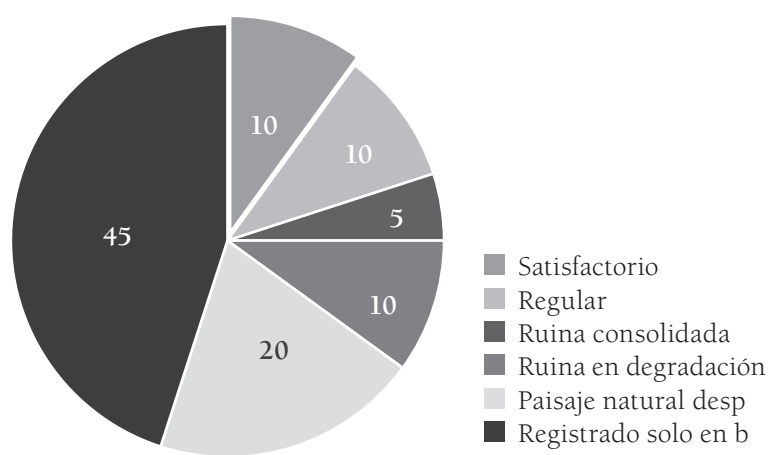

Instituto de Historia y Patrimonio, gabinete y terreno 2010.
Satisfactorio / Regular / Ruina Consolidada / Ruina en Degradación / Paisaje Natural Desprotegido / Lugar Registrado Sólo en Bibliografía (gráfico Nº 1).

En contraste con la información obtenida en las fuentes bibliográficas, el examen en terreno revela que de ese universo estudiado sólo un $10 \%$ de los inmuebles y lugares históricos se encuentra en un satisfactorio estado de conservación. Entre los primeros destacan los fuertes de San Antonio de Ancud y el fortín de Tauco (ambos fuertes se han incorporado a iniciativas turísticas en la zona, materializadas a contar de 1990, tanto en la comuna de Ancud como en la de Chonchi). Responsables de su buen estado de conservación son, en buena medida, la autoridad edilicia y la comunidad.

Los registros en terreno revelan, por otra parte, que un 35\% de los inmuebles históricos analizados bibliográficamente se encuentra en un estado de conservación aceptable. El desmantelamiento de las fortificaciones se puede atribuir, en buena medida, a la falta de conocimiento e interés por la historia. Prueba de ello son los graffitis y el indigno uso que se da a los recintos que superviven. Los restos de muros de albañilería expuestos a la intemperie, en sus llagas y tendeles, han sido colonizados por musgos y gramíneas, que han colonizado las zonas húmedas.

Otro $10 \%$ se encuentra en un estado regular, debido a un destino que honra su historia. Tal es el caso del polvorín de Ancud y Agüi, que en la actualidad 
cumple un rol cívico y social. Pero los casos que se han ganado el respeto, como el señalado ejemplo, son excepcionales. Lo habitual es que los poblados que cumplieron un rol importante en la Campaña de Chiloé sólo sea posible localizarlos a través de documentos escritos, ya que no existen testimonios físicos que los evoquen ni alusión alguna a los acontecimientos históricos que allí acaecieron.

Los lugares históricos en ruinas abundan en la zona. Los hay básicamente de dos tipos: aquellas ruinas consolidadas y otras en degradación.

- Las ruinas consolidadas, protegidas por medidas legales y municipales, no superan el 5\% de los casos analizados. Las distingue una señalética de carácter rústico en que se recalca la importancia histórica y patrimonial del lugar. Un ejemplo es Chacao.

- Las ruinas en degradación constituyen un 10\% del universo estudiado. Se trata de aquellos sitios históricos que, además de ser casi inaccesibles, están mayoritariamente cubiertos de vegetación. A modo de testimonios aparecen cañones, fragmentos de muros, solevantamientos $\mathrm{u}$ otros restos de instalaciones defensivas en medio del follaje. Ejemplos de ello son las fortificaciones de Balcacura y Chaicura.
Algunos de los lugares históricos analizados -un 20\% de ellos- se han tornado cada vez más silvestres, producto de las intensas lluvias, de los vientos sostenidos, de la vegetación invasiva. Debe reconocerse que estos lugares ya han tomado distancia de la memoria de los lugareños: Remolinos, Carelampu, Corona y Coronel.

Del universo total, un $45 \%$ de los casos no fue identificable en terreno, a pesar de que sus coordenadas se descubrieron documentalmente, en especial aquellos registrados en el Flandes Indiano. No se encontró rastros ni testimonios de su emplazamiento. Ejemplos: las fortificaciones de Campo Santo, El Muelle y Astillero.

\section{PERCEPCIÓN HISTÓRICA}

¿Cómo perciben los habitantes de Chiloé sus lugares históricos? Aun cuando este factor conlleva una carga subjetiva, se intenta medir el grado de acercamiento del objeto a la memoria colectiva, el respeto que despierta y el interés por conservarlo en buen estado.

El trabajo de campo reveló que es posible identificar 4 categorías de percepción: Alta, Mediana, Baja y Nula (gráfico No 2). 


\section{GRÁFICO N² 2. LUGARES HISTÓRICOS DE CHILOÉ DE ACUERDO CON LA PERCEPCIÓN HISTÓRICA DE SUS HABITANTES.}
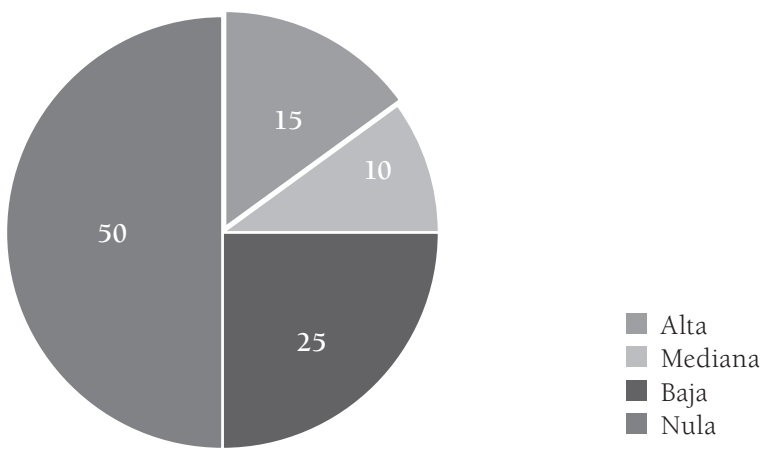

Instituto de Historia y Patrimonio, gabinete y terreno 2010.

Para los habitantes chilotes, un 15\% de los lugares históricos posee una alta percepción: se les identifica su localización, sus características y los relatos asociados a ellos. De los lugares históricos se sabe más allá de sus límites locales, trascendiendo lo próximo. Conforme se ha fomentado la actividad turística han cobrado presencia creciente las fortificaciones de Agüi, San Antonio y Tauco.

En segundo término están los lugares con una mediana percepción histórica, lo que corresponde a un $10 \%$ de los casos estudiados. Son aquellos recordables por habitantes que residen en el área cercana al lugar histórico. El conocimiento de estos lugares se hace más nítido entre los adultos y adultos mayores, que aún conservan evocaciones, derivadas de su propia infancia o del relato oral de sus ascendientes. Destacan el Polvorín de Ancud y Chacao.

Los lugares históricos con baja percepción -un 25\% del total de los casos- sólo logran ser identificados por habitantes mayores de 70 años de edad y por profesionales como historiadores, antropólogos, sociólogos, arquitectos. Especialistas que, en definitiva, se han dedicado al estudio de las Ciencias Sociales. En este segmento se reconocen Carelmapu, Corona, Coronel, Balcacura y Chaicura.

Por último, cabe considerar que un 50\% de los lugares históricos presenta una nula percepción histórica y sólo han sido registrados por expertos en la Historia de Chiloé. El conocimiento de ellos se sustenta en documentos históricos con acceso restringido, como crónicas, cartas, bitácoras, cartografías y otros escritos de la época en que esos lugares aparecen registrados. No es extraño, en consecuencia, que sean ignorados por la mayoría de los habitantes de Chiloé. Destacan en este grupo el centinela de Guapacho y la batería de Pampa de Lobos. Existen otros, incluso, que ni siquiera fue posible localizar en el trabajo de terreno.

\section{IMPORTANCIA HISTÓRICA}

La cantidad de veces que aparece una fortificación como lugar o sitio histórico en los documentos relacionados con la Campaña de Chiloé (1820-1826) y el Flandes Indiano del sistema defensivo del archipiélago revela la importancia de cada caso. Para este 
propósito se examinó, en gabinete, a diversos autores, todos historiadores(los 3 últimosdedicadosa Chiloé):

- Diego Barros Arana.

- Francisco Antonio Encina.

- Rodolfo Urbina.

- Osvaldo Silva.

- Gabriel Guarda OSB.

- Pedro J. Barrientos.

- Dante Montiel.

- José Ulloa.

- Carlos López Urrutia.

- Gavino Mansilla.

- Rodrigo Fuenzalida Bade.

- Carlos de Berenger.

- José Manuel de Moraleda.

- Javier Vargas Guarategua.

Adicionalmente, se revisaron las memorias militares de Jorge Beauchef, Guillermo de Vic Tupper, Thomas Cochrane, Antonio de Quintanilla y Williams Miller. A partir de toda esta documentación se obtuvo un total de 20 lugares históricos en Chiloé. La información bibliográfica recopilada permitió determinar cuatro rangos de importancia histórica: Alta, Mediana, Baja y Casi Nula (gráfico Nº ).

De acuerdo con el gráfico $\mathrm{N}^{\circ} 3$, un 25\% de los lugares históricos chilotes detectados en la etapa de gabinete -incluidos los fuertes- se han considerado de Alta Importancia (han sido mencionados

\section{GRÁFICO N³. LUGARES Y FUERTES HISTÓRICOS DE CHILOÉ DE ACUERDO A SU IMPORTANCIA.}
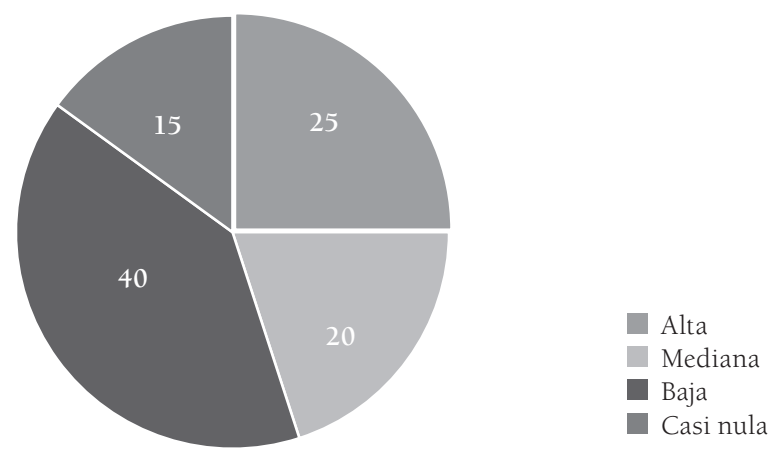

Instituto de Historia y Patrimonio, gabinete y terreno 2010

entre 8 y 13 veces por los autores citados) porque consignan información que contiene, como mínimo, una descripción de las características físicas, la localización, la cronología y las medidas defensivas, tanto de las fortificaciones hispanas como de los lugares importantes de la Campaña de Chiloé (1820-1826). Ejemplos de ello son el Fuerte Agüi y la Batería San Antonio.

El grupo que está en segundo lugar se ha considerado, en la revisión bibliográfica, de Mediana Importancia (los casos han sido referidos entre 4 y 7 veces en los documentos). Corresponde a un 20\% del catastro total. La información que entregan corresponde a una reseña general, datos sobre su emplazamiento y su rol de sitio histórico en Chiloé. Destacan Balcacura, Fuerte Real San Carlos y Poquillihue. 
Los lugares con baja importancia -que alcanzan un 40\% - sólo aparecen citados en la bibliografía en 2 ó 4 ocasiones y su información se reduce a una mínima reseña de lo acontecido en ellos. Entre esos sitios históricos se encuentran Guapacho, El Muelle, Remolinos y Coronel.

Por último, están los lugares históricos con una casi Nula Importancia. Corresponden a un $15 \%$ de los casos. Sólo se les menciona una vez en los escritos y presentan una reseña imprecisa de los hechos acontecidos. Tal es el caso de Chaicura, el fuerte y batería marítima de Castro.

\section{ACCESIBILIDAD}

¿Qué tan accesibles son los lugares históricos de Chiloé? El clima severo ya es un factor altamente incidente. Pero también lo es el tipo de camino que conduce hasta los puntos de destino. Por cierto, el grado de accesibilidad guarda directa relación con el estado de conservación de los lugares de interés histórico.

Para definir la calidad de los caminos involucrados y, por ende, la expedición para transitarlos, se consideró, en el análisis, su material de superficie, a saber:

- Pavimento

- Ripio

- Huella o tierra

- Sin acceso

156 revista invi № 73 / Noviembre 2011 / Volumen № 26: 133-165

\section{GRÁFICO N4. LUGARES HISTÓRICOS DE CHILOÉ DE ACUERDO AL CRITERIO DE ACCESIBILIDAD.}
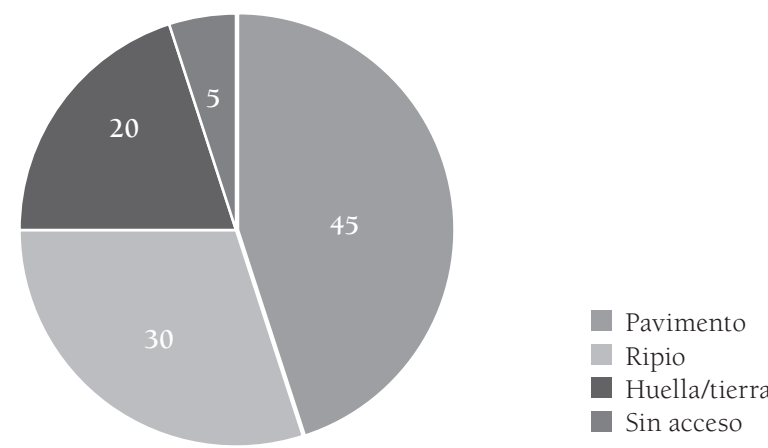

Instituto de Historia y Patrimonio, gabinete y terreno 2010.

Un 45\% de las vías son pavimentadas. Corresponden a un total de $142 \mathrm{~km}$ que se distribuyen en la Ruta 5 Sur (tramo Chacao-Ancud y tramo AncudChonchi). En estos tramos se localizan la Batería San Antonio, el Polvorín de Ancud y Castro.

Las vías ripiadas corresponden a un 30\%; alcanzan una extensión aproximada de $9 \mathrm{~km}$ en Tauco, Chaicura, Balcacura, Carelmapu, Coronel y Agüi.

Los caminos de huellas o tierra -un 20\% de los casos- alcanzan aproximadamente a $70 \mathrm{~km}$. La inclemencia del clima, sumada a una geografía irregular e inhóspita y la exuberancia de su vegetación nativa, se traducen en un tránsito intermitente, que hace difícil la conectividad. Es el caso de Corona, Remolinos y Pampa de Lobos. 
El 5\% de los casos restantes corresponde a los sitios históricos que están desconectados por vía terrestre. Llegar a destino implica cruzar por una densa foresta y bordear fatigosamente la costa. La vía marítima no ofrece menos dificultades. Como el caso de Guapacho.

\section{SEÑALÉTICA}

Un recorrido por la zona demuestra que la señalética que anuncia los lugares de interés histórico no constituye una preocupación importante para las autoridades locales.

Se detectaron 4 categorías: Buena, Regular, Mala e Inexistente (gráfico N5).

\section{GRÁFICO N5. LUGARES HISTÓRICOS DE CHILOÉ DE ACUERDO AL CRITERIO DE SEÑALÉTICA.}
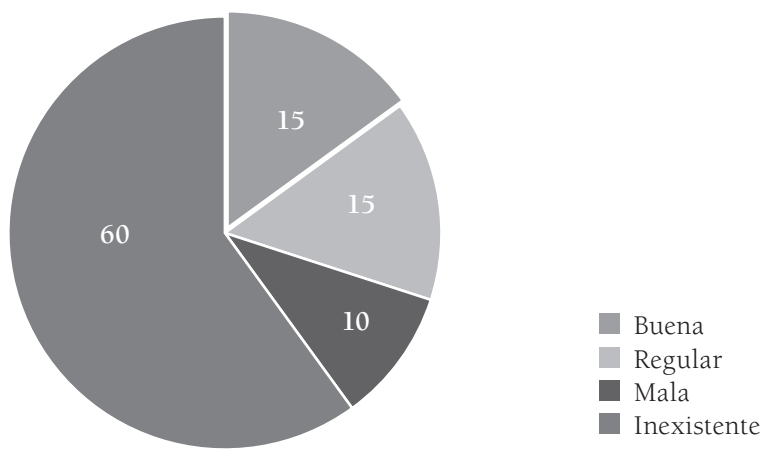

Instituto de Historia y Patrimonio, gabinete y terreno 2010.
Del total de 20 sitios detectados en la bibliografía, un 15\% de ellos posee una señalización Buena: contienen información suficiente acerca de la localización y del rol histórico que representan. Es el caso de las baterías de San Antonio, El Polvorín y Agüi.

Un 15\% de los lugares históricos detectados presenta una señalética Regular, que se limita a indicar su ubicación. Tal es el caso de Tauco, Chaicura y Balcacura.

Del mismo universo registrado, un 10\% presenta una señalética Mala, especialmente por las deficientes condiciones en que se encuentra: en la mayoría de esos casos, la lectura de ellos resulta casi imposible. Ejemplos: Remolinos y Chacao.

Los lugares históricos que no poseen señalética alguna alcanzan un 60\% de los casos. Entre ellos, Carelmapu, Astilleros, La Poza, Coronel y otros.

\section{CANTIDAD DE VISITAS QUE RECIBEN LOS LUGARES HISTÓRICOS DE CHILOÉ}

La información proporcionada por SERNATUR Región de Los Lagos, complementada con la que recolectaron en terreno los investigadores del IHP (2010), permite colegir que los sitios estudiados son escasamente visitados. Se clasificó la asistencia en: Alta, Media, Baja y Nula (gráfico Nº 6). 


\section{GRÁFICO N 6. ASISTENCIA A LUGARES HISTÓRICOS DE CHILOÉ.}

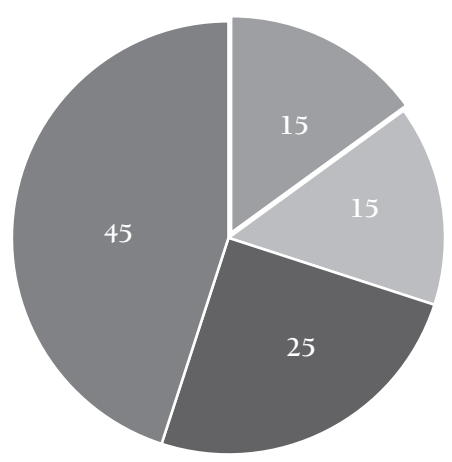

Asistencia alta

Asistencia media

- Asistencia baja

Asistencia nula

Fuente: SERNATUR, Región de Los Lagos e Instituto de Historia y Patrimonio, gabinete y terreno 2010

Los lugares en los cuales se produce una Alta Asistencia suman un 15\% (algo así como 2.000 personas por año). Los visitantes provienen, en general, del propio archipiélago de Chiloé. Estos lugares visitados son de fácil accesibilidad durante buena parte del año, y casi siempre están incorporados a los programas de turismo que organizan las municipalidades. Eso ocurre en San Antonio de Ancud, Tauco y El Polvorín.

Otro 15\% de los lugares registra entre 500 a 1.000 visitantes por año. En el panorama general, se ha considerado ésta como Asistencia Media. Los interesados son, en su mayoría, profesionales de las ciencias sociales (antropólogos, arqueólogos, historiadores, arquitectos, profesores o afines), o estudiantes de los distintos niveles de enseñanza. Por estar condicionada por el clima y, consiguientemente, por las posibilidades de acceso, la asistencia sube en los meses estivales. Ejemplos: Agüi, Carelmapu y Chacao.

Cuando las visitas a los lugares históricos no alcanzan las 200 personas al año se estima una Asistencia Baja. Dentro del total corresponde a un 25\% del universo estudiado. La concurrencia de visitantes está limitada por la accesibilidad, el clima y la invasión de vegetación nativa. Es el caso de Corona, Chaicura, Balcacura, Astilleros y Remolinos.

Muchos de los lugares históricos se han ido extinguiendo. Algunos se han deshecho materialmente. Otros han sido sepultados por la vegetación silvestre o dominados por el bosque nativo chilote. Incide en su condición de abandono, además, la dificultad para acceder a ellos, la geografía desconocida y el clima habitualmente inhóspito.

Existen, por último, algunos sitios que no registran visitas. Del universo analizado alcanzan el 45\%. A modo de ejemplo, Guapacho, La Poza, Pampa de Lobos, Coronel y otros.

\section{SECUENCIA EVOLUTIVA DE LOS ESPACIOS HISTÓRICOS PRESENTES EN EL ARCHIPIÉLAGO DE CHILOÉ}

Para elaborar esta secuencia y determinar las fases que la componen se combinaron y ponderaron 
las variables analizadas anteriormente. Complementariamente, aplicando el método Delphi, se entrevistó a expertos (historiadores, arquitectos, antropólogos, militares y otros profesionales del área social) que conocen sobre el tema histórico y defensivo de Chiloé.

El resultado, tras el análisis cualitativo y cuantitativo, fue el siguiente:

- Estado de conservación: 30\%.

- Percepción histórica: 25\%.

- Importancia histórica: 20\%.

- Accesibilidad: 12\%.

- Señalética: $8 \%$.

- Asistencia de visitantes: 5\%.

Estas valorizaciones permiten ordenar, de manera progresiva, los 20 lugares históricos previamente determinados. La secuencia evolutiva hace referencia a aquellos lugares con mejores condiciones y que forman parte de los programas de turismo. Pero también incorpora a aquellos lugares que sólo aparecen en la bibliografía histórica, patrimonial y defensiva de Chiloé (gráfico N7).

\section{GRÁFICO N 7 . VALORES PONDERADOS DE LOS LUGARES HISTÓRICOS DE CHILOÉ.}

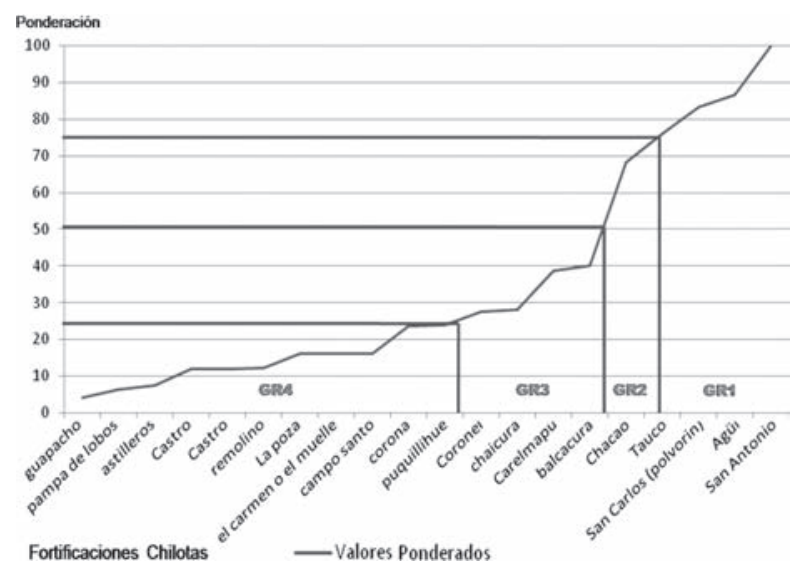

Instituto de Historia y Patrimonio, gabinete y terreno 2010.

Tal como se ha revelado en los gráficos anteriores, cada lugar histórico está condicionado por un cúmulo de factores que, fundidos, determinan un cierto resultado. Como es de esperar, en cada uno de los casos esos factores confluyen con distinto grado de intensidad, atendiendo a su situación particular. 
Definidos los factores, se ha elaborado una matriz ordenadora que da cuenta, en términos ideales, de sus respectivos grados de valoración. Esta matriz contribuye a precisar el actual estado del sistema defensivo español de Chiloé, así como aquellos acontecimientos acaecidos en la Campaña de Chiloé (1820-1826). En la medida que la mayor parte de los factores de análisis de cada uno de esos bienes patrimoniales se aproxime a la valoración máxima, las posibilidades de recuperación de ese bien serán mayores. Y, por lo tanto, susceptibles de ser incorporados a un circuito de turismo cultural.

Es preciso reconocer que ninguno de los ejemplos estudiados se ajusta exactamente a alguno de los Grados de Recuperación establecidos en la Matriz ideal. Aun así, los ejemplos se adscriben a aquel grado que les resulta más cercano (tabla $N^{\circ} 1$ ).

\section{GRADO DE RECUPERACIÓN 1}

Alcanzar este nivel implica que el Sitio que forma parte del Sistema Defensivo Español (bien tangible) o el Acontecimiento que corresponde a la Campaña de Chiloé (bien intangible) debe cumplir las siguientes condiciones:

- Estado de Conservación: Satisfactorio (tanto en su condición estructural como en su imagen aparente).

- Percepción Histórica: Alta (lo que significa que el lugar está incorporado al conocimien- to de los habitantes, en el nivel local y en el regional).

- Importancia Histórica: Alta (el bien ha cumplido un destacado papel en el curso de los hechos pasados).

- Accesibilidad: Buena (expedita, con carreteras pavimentadas).

- Señalética: Buena (además de expresar el topónimo, incluye información sobre la estructura y el rol que ejerció el lugar histórico, tanto en el sistema defensivo hispano como en la Campaña de Chiloé).

- Cantidad de Visitantes: Alta (durante gran parte del año).

A este Grado de Recuperación se aproximan las fortalezas españolas de Tauco, El Polvorín, Agüi y San Antonio.

\section{GRADO DE RECUPERACIÓN 2}

- Estado de Conservación: Regular (dentro de una estructura relativamente sana, se advierten daños superficiales y nula manutención de sus elementos superficiales. La vegetación y la humedad son enemigos permanentes).

- Percepción Histórica: Mediana (los lugares son reconocidos principalmente por adultos que viven en localidades aledañas. También son motivo de atención de estudiantes y profesionales dedicados al estudio de la historia de Chiloé). 
TABLA N¹ MATRIZ DE GRADOS DE RECUPERACIÓN DE LOS LUGARES HISTÓRICOS DE CHILOÉ.

\begin{tabular}{lllllll} 
& Estado de & Percepción & Importancia & Accesibilidad & Señalética & Cantidad de \\
& Conservación & Histórica & Histórica & & & Visitantes \\
\hline 1 & Satisfactorio & Alta & Alta & Buena & Buena & Alta \\
\hline 2 & Regular & Mediana & Mediana & Regular & Regular & Media \\
\hline 3 & Mala & Baja & Baja & Mala & Mala & Baja \\
\hline 4 & Pésima & Nula & Nula & Inexistente & Inexistente & Nula \\
\hline
\end{tabular}

Instituto de Historia y Patrimonio, gabinete y terreno 2010.

- Importancia Histórica: Mediana (el caso aparece vagamente mencionado en algún texto)

- Accesibilidad: Regular (en general, se trata de caminos ripiados, algo incómodos).

- Señalética: Regular (sólo se indica el topónimo, pero no entrega información histórica).

- Cantidad de Visitantes: Media (se produce una relación directa con la calidad de la accesibilidad).

A este Grado de Recuperación se podría adscribir solamente a Chacao.

\section{GRADO DE RECUPERACIÓN 3}

- Estado de Conservación: Malo (en el caso de estructuras defensivas, se trata, por lo general, de ruinas con algún nivel de protección. No es extraño descubrir cañones antiguos o montículos que encubren remanentes de muros. Si son lugares históricos, permanecen como sitios eriazos o, en su defecto, se encuentran ocultos por la vegetación).

- Percepción Histórica: Baja (sólo son apreciados por estudiantes y profesionales expertos en la historia de Chiloé. De hecho, en los textos históricos son escasamente mencionados y su información es citada de manera imprecisa).

- Importancia Histórica: Baja (no se menciona en textos).

- Accesibilidad: Mala (casi siempre son caminos de tierra o huellas que pierden fácilmente la continuidad a causa del clima severo).

- Señalética: Mala (aparecen datos incompletos y muy poco orientadores).

- Cantidad de Visitantes: Baja (la mala accesibilidad, la señalética pobre y la mínima difusión redundan en la escasa presencia de visitantes a estos lugares).

revista invi № 73 / Noviembre 2011 / Volumen № 26: 133-165 161 
A este grupo se asimilan Coronel, Chaicura, Balcacura y Carelmapu.

\section{GRADO DE RECUPERACIÓN 4}

- Estado de Conservación: Pésimo (en el caso de las edificaciones defensivas se trata, por lo general, de ruinas en la más completa degradación. Es común que estén sepultadas bajo una densa masa boscosa o vegetal. Y si es un sitio, suele estar enteramente desamparado. Algunos de ellos sólo superviven en archivos documentales)

- Percepción Histórica: Nula (ni siquiera los propios lugareños tienen conciencia de que existen)

- Importancia Histórica: Nula (el que no se conozcan les hace desaparecer del ámbito de la cultura).

- Accesibilidad: Inexistente.

- Señalética: Inexistente.

\section{- Cantidad de Visitantes: Nula.}

Se pueden asociar a este grupo los siguientes sitios: Guapacho, La Poza, El Muelle, Campo Santo, entre otros.

El modelo expuesto, que procura la recuperación de ciertos bienes culturales, conforme sea su grado de evolución -los fuertes y sitios históricos, en este caso- permite dar cuenta de su situación actual y prefigurar la gestión que exige la efectiva conservación de cada una de las piezas de valor involucradas. Se trata, en último término, de evitar la pérdida irreparable de un patrimonio material e inmaterial que merece ser parte de la memoria colectiva del pueblo chilote (ver figura 11).

\section{Consideraciones finales}

Desde la época colonial hasta nuestros días, los fuertes hispanos de Chiloé han sido objeto de una indiferencia sostenida por parte de lugareños y expertos. Más que reconocer su auténtico valor cultural, como sucede en otras latitudes -el Caribe, por ejemplo-, estos enclaves se han transformado en inútiles ruinas, sitios eriazos y deprimentes vertederos.

Contribuye a este desolador panorama, ciertamente, la desarticulada geografía de Chiloé y el olvido por parte de la comunidad local, que se inclina a aceptar otras expresiones arquitectónicas, casi siempre ajenas a su identidad y su cultura. Se explica, entonces, que la mayoría de estas fortificaciones sólo haya sido descrita y referenciada por documentos de la época colonial, por escritos temáticos especializados y por el relato de adultos mayores de los sitios donde se emplazaban.

Parece necesario emprender acciones y diseñar fórmulas efectivas que propicien el resguardo de la tradición oral, especialmente en lo que concierne a los fuertes hispanos de Chiloé. Es deseable que 


\section{FIGURA 11. APLICACIÓN DE LA MATRIZ DE GRADOS DE RECUPERACIÓN DE LOS FUERTES HISPÁNICOS DE CHILOÉ.}

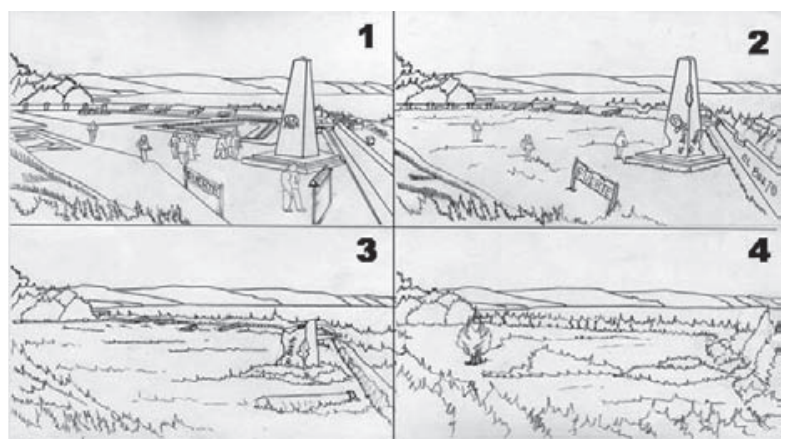

Diagrama según del grado de recuperación de un lugar histórico de Chiloé. 1.- Satisfactorio. 2.- Regular. 3.- Malo. 4.- Pésimo. IHP. 2010

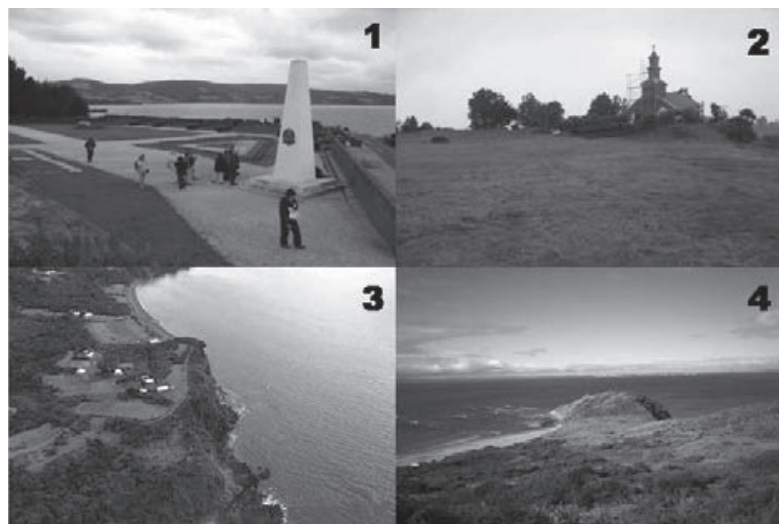

Modelo evolutivo de un espado histórico, aplicado a las fortalezas de Chiloé. Etapa 1: Batería de San Antonio. Etapa 2: Fuerte de Chacao. Etapa 3: Batería de Chaicura. Etapa 4: Batería de Guapacho. IHP. 2010.

Instituto de Historia y Patrimonio 2010. se considere un archivo escrito o un plan de educación en las aulas insulares que refiera decididamente la historia local. De esta manera, se evitará la inexactitud histórica y la proliferación de versiones que no hacen sino producir confusión en torno a los hechos acontecidos en el área.

Merece la pena, por otra parte, resaltar el rol de ciertas instituciones públicas y privadas que se han comprometido progresivamente con la salvaguarda del patrimonio. Merced a esta asociatividad es posible implementar acciones estratégicas pertinentes para la materialización de un proyecto tan ambicioso como puede ser una Ruta Turística Histórica y Patrimonial en la zona. A través de esta ruta merece la pena incorporar hitos patrimoniales que bien podrían constituirse en focos de atracción secundarios, aceptando que la trayectoria crítica está conformada por las antiguas fortificaciones hispanas.

Finalmente, Chiloé no sólo debe ser reconocido por sus atributos naturales, por su geografía y sus paisajes, sino también por su magnífica producción arquitectónica. Amén de iglesias, palafitos y fogones, se cuenta con los fuertes hispanos y los lugares históricos asociados a las batallas de la Campaña Chiloé (1823-1826). El desafío es conseguir la revalorización y la puesta en valor de cada uno de estos sitios emblemáticos, haciendo hincapié en la recuperación del patrimonio intangible que irradia cada uno de ellos. 


\section{Bibliografía}

BARRIENTOS, Pedro J. Historia de Chiloé. $1^{\text {a }}$ ed. Ancud, Chile [s.n]. 1948. 252 p.

BERENGER, Carlos de. Relación geográfica de la Provincia de Chiloé. Introducción y notas explicativas de Nicolás Anrique. $1^{\circ}$ ed. Santiago, Chile, Cervantes. 1893. 67 p.

CÁRDENAS, Renato. El libro de los lugares de Chiloé. Ancud, Chiloé [s.n]. 1997. 102 p.

COCHRANE, Thomas. Memorias de Lord Cochrane. $1^{\text {a }}$ ed. Lima, Perú, Imprenta José Masías. 1863. 87 p.

FELIÚ CRUZ, Guillermo. Memorias militares para servir a la historia de la independencia de Chile del Coronel Jorge Beauchef: 1817-1829; y, Epistolario (1815-1840). Santiago de Chile, Andrés Bello. 1964. $557 \mathrm{p}$

FUENZALIDA BADE, Rodrigo. La armada de Chile: desde la alborada al sesquicenterario (1813-1968) $2^{\mathrm{a}}$ ed. Santiago de Chile [s.n]. 1978. 4 v., 1435 p.

GUARDA, Gabriel y MORENO JERIA, Rodrigo. Monumenta cartographica Chiloensia: misión territorial y defensa 1596-1826. Santiago, Chile, Andros. 2008. 205 p.

GUARDA, Gabriel. Flandes Indiano. Las fortificaciones del Reino de Chile. 1541-1826. Santiago, Chile, Ediciones Universidad Católica de Chile. 1990. $425 \mathrm{p}$.
GUARDA, Gabriel. Las fortificaciones del Reino de Chile y su arquitectura. En Boletín de la Academia Chilena de la Historia. (87): 223-262, 1973.

LÓPEZ URRUTIA, Carlos. Historia de la Marina de Chile. Santiago de Chile, Andrés Bello. 1969. 448 p.

MANSILLA, Gavino. Carta a D. Manuel Olaguez Feliú. [En línea]. Memoria Chilena. 1818. [Fecha de consulta: 22 de Junio de 2009]. Disponible en: http:// www.memoriachilena.cl//temas/documento_detalle2.asp?id=MC0007565

MORALEDA, José Manuel de. Exploraciones geográficas e hidrográficas. Santiago, Chile, Imprenta Nacional. 1888. 533 p.

ÓRDENES, Manuel. Estudio preliminar de los espacios históricos chilotes y su valorización como lugares de Patrimonio Cultural. Campaña de Chiloé (1820-1826). Santiago, Chile, Instituto de Restauración Arquitectónica, Facultad de Arquitectura y Urbanismo, Universidad de Chile. 2008. Práctica Profesional de Geografía.

TUPPER, Ferdinand. Memorias del Coronel Tupper (1800-1830): Diario de campaña y documentos. Santiago de Chile, Francisco de Aguirre. 1972. $223 \mathrm{p}$.

ULLOA, José. La huella de Beauchef. [video] Santiago, Chile, Valdivia Film, Apata Producciones, Jirafa. 2005 . 
ULLOA, José. Las fortificaciones hispánicas de la Bahía de Ancud y Península de Lacuy. Ancud, Chile, Imprenta Cóndor. 1996. 52 p.

URBINA BURGOS, Rodolfo. La periferia meridional indiana. Chiloé en el Siglo XVIII. Valparaíso, Chile, Ediciones Universitarias de Valparaíso. 1983. 205 p.

VARGAS GUARATEGUA, Javier. Chiloé: el último reducto español en América del Sur. Revista Diplomacia. (106): 56-92, 2006.

VARGAS GUARATEGUA, Javier. El antemural del Pacífico y Chiloé en el periodo indiano. Revista Diplomacia. (110): 95-121, enero 2007. 